\title{
Collaborative Italian: Using technology to support student-led language teaching
}

\author{
Cecilia Goria \\ cecilia.goria@nottingham.ac.uk \\ UNIVERSITY OF NOTTINGHAM
}

\begin{abstract}
Collaborative Italian - Collit — is an online language learning program for adult students of Italian in higher education with at least a B1 level of the Common European Framework. Collit is free, open and extracurriculum.

Collit provides the learners with a communicative learning experience based on collaboration and social interaction. It promotes social constructivism and embraces Web 2.0 pedagogies by relying on the openness of the online environment and social media. Collit emphasises ownership of learning by encouraging student-controlled intended learning outcomes and tasks, and student-generated learning content, consistent with the cognitive and the experiential approaches to course design onto which Collit is theoretically grounded.

On this basis, Collit addresses questions concerned with the effectiveness of open pedagogies for student-led language learning. This contribution presents Collit as a case study for the investigation of novel language learning dynamics supported by the web and social media.
\end{abstract}

Key words: collaboration, openness, student-generated content, Pedagogy 2.0

\section{Résumé}

Collaborative Italian - Collit — est un programme d'apprentissage des langues à distance dans l'enseignement supérieur. Il s'adresse aux étudiants adultes ayant au moins un niveau B1 du Cadre européen commun de référence en italien. C'est un programme gratuit, ouvert et extracurriculaire.

Collit fournit aux apprenants une expérience globale d'apprentissage communicatif des langues basée sur la collaboration et l'interaction sociale. Il favorise le constructivisme social et embrasse le Web 2.0 par les pédagogies s'appuyant sur l'ouverture de l'environnement en ligne et des médias sociaux. L'appropriation de l'apprentissage est valorisée car les apprenants créent leurs propres contenus pédagogiques, objectifs 
et tâches, conformément aux approches cognitives et empiriques du programme.

Collit aborde des questions sur l'efficacité des pédagogies ouvertes pour l'apprentissage des langues dirigé par les étudiants. Cette contribution présente Collit, comme une étude de cas dans les recherches sur les nouvelles dynamiques d'apprentissage des langues basées sur le web et les médias sociaux.

Mots-clés : collaboration, ouverture, contenu généré par les étudiants, pédagogie 2.0

\section{Introduction}

Web 2.0 has transformed learning from consumption of resources to active creation of content to be shared with a wide audience or a given community of learners. In view of this transformation, McLoughlin and Lee (2008) propose an approach to pedagogy, Pedagogy 2.0, defined as "a learner-based, communal, media-rich and flexible approach [which] uses social software tools to enable the development of dynamic communities through connectivity, communication, and participation" (p. 3). As the authors suggest, the difference between Pedagogy 2.00 and more traditional approaches lies in the use of social software tools to create personalised learning and connect it to a wider audience of peers, instructors, subject experts and the community. This model capitalises on personalization, participation and content creation for the benefit of learning experiences that are more "productive, engaging, and community based [...]" (p. 5).

A more recent study on the role of Web 2.0 (Pop, 2010) in education, points to its benefits with specific reference to language learning. In her study, Pop finds that the benefits of employing Pedagogy 2.0 in the foreign language classroom are twofold: it offers the students greater opportunity to practice the target language and it increases motivation, confidence and disposition as the result of student involvement in class and out of class activities and practices which are crucial for communicative foreign language learning.

The open dialogue onto which Pedagogy 2.0 relies through the use of social software is only one of the aspects of the notion of openness that has received increasing attention in education with the development of Open Courses, Open Educational Resources and Open Access(ibility). The recent rise and spread of MOOCs (Massive Open Online Courses) and the pedagogical model that they promote (Cormier and Siemens, 2010) is amongst latest expressions of such a trend. MOOCs are open educational initiatives that recruit globally and promote a participatory pedagogy model by which, under the educator's guidance, "learners are expected to actively contribute to the formation of the curriculum (community-as-curriculum model) through conversations, discus- 
sions and interactions" (p. 36).

The aim of this contribution is to present the design of an online module in Italian language, Collaborative Italian (Collit), designed to provide the empirical ground to test:

- the effectiveness of Pedagogy 2.0 to support student-led language learning and learner-generated content;

- the effectiveness of a language learning environment modelled on MOOCs' community-as-curriculum approach.

The novelty of this study lies in the adoption of principles of Pedagogy 2.0 and some features of MOOCs for language teaching and learning.

\subsection{Collit: An overview}

Collit is a pilot study which involves an online language programme which recruits from registered students of the University, from alumni and from members of staff. It targets individuals with a level of Italian equivalent to at least B1 of the Common European Framework, is optional, extra curriculum, delivered exclusively online and based on wiki activities (Pbworks) and weekly online meetings (Skype). Furthermore, Collit is open curriculum in that it relies on the students' contributions in evaluating and selecting resources and creating activities to be shared within the learning group.

Collit has the overall teacher-determined objective to improve students' communicative proficiency, and several specific students-controlled intended learning outcomes (ILOs, borrowed from Biggs, 2003). These are:

- achievement of a level of language skills (listening, reading, speaking and writing) above the B1 level of the Common European Framework;

- acquisition of the ability to deal adequately with real-life situation in the target language;

- enrichment of cultural and linguistic awareness;

- consolidation and extension of grammatical knowledge.

Overall, Collit provides the students with an informal communicative experience based on collaboration, knowledge sharing, interaction and social immersion through the formation of a learning community. It does so by implementing constructivist and experiential principles while embracing open pedagogies for language learning.

The remaining of this paper is organised as follows: the next section will provide an outline of the approaches to course design which ground the design of Collit. Section 3 will present and theoretically contextualize the main 
features of Collit. Section 4 will outline a number of preliminary findings and section 5 will conclude this paper.

\section{The theoretical basis}

Toohey (1999) provides a typology of five approaches to course design, namely the traditional approach; the performance approach; the cognitive approach; the experiential approach and the socially critical approach, based on their view of knowledge, their methods for facilitating learning, their view of the role of the teacher, their ideas on curriculum content and organization, their goals and objectives and their expression. Collit promotes a combination of two of these approaches, that is, the cognitive and experiential approaches, to consider the benefits of such a combination within the context of language learning. The reason for such a choice is due to the fact that these two approaches are particularly consistent with the principles of Pedagogy 2.0 outlined earlier.

The cognitive approach (Rovai, 2004, among others) is highly influenced by the theory of constructivism according to which learners construct meaning through active participation (Perkins, 2006) in the learning process rather than passive consumption of information and memorization (Oliver and Herrington, 2003). Knowledge is built through social interactions (Vygotsky, 1978), that is, dialogue, knowledge sharing, collaboration, negotiation and discussions with others. A cognitive approach-designed course (Toohey, 1999) promotes the personal construction of knowledge, encourages the use and development of rigorous analytical thinking, focuses on the depth of the curriculum content rather than on quantity and uses real-world resources for problem identification and solving. Furthermore, it provides resources for independent investigation and may involve self and peer assessment. Finally, the teacher's role is to elicit and facilitate levels of analysis, which the learners would not have reached on their own.

Theories of experiential learning (Kolb, 1993, among others) regard learners' experience as the foundation and stimulus for learning and maintain that the creation of knowledge takes place through the transformation of experience based on observation and reflection (Usher, Bryant and Johnston, 1999). An experiential view of learning focuses on learning as a process of adaptation rather than content and outcomes (Kolb, 1993) and on knowledge as "derived and tested out in the experiences of the learner"(p. 145). The experiential approach to course design (Toohey, 1999) promotes learning which is personally relevant to the learner, mutual teacher-student respect, collaboration, support, openness and authenticity. The teacher's role is to assist planning, facilitate group-work and offer guidance while students determine their own learning goals and may be involved in the planning of the unit.

Building on the coherence between principles of open pedagogies and fea- 
tures of the cognitive and experiential approaches, Collit, in implementing Pedagogy 2.0, combines these two approaches promoting in particular:

- social interaction and collaboration to encourage communication and knowledge sharing;

- reflection and analytical thinking of one's own knowledge and that of others;

- learners' responsibility for their own learning paths and outcomes;

- knowledge which is personally relevant and built from experience;

- role of the teacher as facilitator and source of guidance for students' own initiative.

Furthermore, Collit is an informal learning environment and its design has been informed by Knowles's (1998) idea (in Smith, 2002) that an informal educational program uses group activities (cf. section 3 for an example) to which students adhere voluntarily. It is also optional and therefore relies on the internal (Smith, 2002) motivational properties of adult learning, on adults' need to be in charge of their own learning and apply skills or knowledge to the real world. These premises of adult learning are significantly aligned with the principles of cognitive and experiential theories of learning outlined above.

According to Biggs (2003) the quality of learning depends upon the constructive alignment between teaching methods, assessment and ILOs. "The 'constructive' aspect refers to the idea that students construct meaning through relevant learning activities. [...] The 'alignment' aspect refers to what the teacher does, which is to set up a learning environment that supports the learning activities appropriate to achieving the desired learning outcomes" (p. 2). In Collit, an overarching constructive alignment is realised by incorporating interactive and collaborative activities that are constructivist in fostering knowledge building through social practice and are aligned with the overall course objective to enhance communicative skills.

It was mentioned earlier that recent developments in innovative pedagogies have seen the emergence of open educational initiatives called MOOCs. A "MOOC, or connectivist, course" (Cormier and Siemens 2010, p. 32) is an online course, usually run with a large number of learners, which is open in content and practice, has an open curriculum and relies on open online discourse. Central to MOOCs is the participants' freedom "to join, create, interact, analyse, and reflect according to his or her own learning needs" (Koutropoulos et al., 2012, p. 1). The high number of participants enhances the course experience by enriching the conversations. This leads to a complex but self-organized system (deWaard et al., 2011).

MOOCs are open in different ways. They are: 
- open in the sense of open practice. This refers to the transparency of the activities and the dialogue between the participants;

- open in providing open access to individuals joining the course regardless of their affiliation to an institution;

- open in supporting learners who have themselves become open to less traditional educational models. That is, learners "capable to engage in their own learning outside the classroom structure" (and Siemens, 2010, p. 35);

- open in promoting the community-as-curriculum model, in which the position of the curriculum is inverted from being a prerequisite of the course to being its output.

Collit is not a fully-fledged MOOC, mainly because of its small size - five regular participants against the hundreds in MOOCs (the term T(iny)OOCs (Goria, 2012) may be more appropriate). Nonetheless, it incorporates several MOOClike features especially those related to openness. Like a MOOC, Collit is an educational initiative which is open in a number of ways:

- it recruits openly from a diverse group of university related individuals (see section 1.1), provided they have the appropriate level of linguistic competence;

- it relies on existing open online learning resources and generates new ones (see section 3);

- it is based on open and transparent dialogues between student-student and student-tutor;

- it is open curriculum.

Further research around Collit is in order to focus on the issue of critical mass in open language learning.

\section{The study: The design of Collit}

To maximize the implementation of Pedagogy 2.0 and the application of the principles of the cognitive and experiential approaches (section 2), the main activities of Collit pivot around a wiki platform. This is because wikis allow users to create, share and edit the (written) contributions of the participants. Hence wikis are the ideal tools for promoting collaborative creation of knowledge (Moskaliuk, Kimmerle and Cress, 2009).

The students populate the wiki: they are required to select the topics onto which they want to work, search, evaluate, select and share online resources to develop themes in accordance to their own needs and interests. The students 
are also required to create content and activities from their resources to be used as learning materials for their peers. For example, four weeks into the module, the students were asked to organize a group project. They met online, decided to work on a popular Italian film, distributed the tasks amongst each other, and published on the wiki a report — in the target language — of their decision making process, to which the tutor provided initial feedback. In the subsequent weeks, each student completed and published his or her tasks creating further learning materials to be used by all students to deepen the chosen topic and explore, under tutor's guidance, further resources.

The strengths of the wiki are several. First, it provides the students with the opportunity to improve language skills, in particular writing in the target language. It does so through individual practice as well as knowledge sharing. In line with the cognitive approach to course design (section 2), knowledge sharing is particularly effective for the creation of new knowledge which in a wiki emerges from the incongruity between people's existing knowledge and the shared content of the wiki (Moskaliuk et al., 2009).

Second, Collit's wiki supports development of language awareness through collaboration, a feature which is central to both the cognitive and the experiential approaches (section 2) in the following ways: it is the basis of the construction of knowledge (Jonassen, 1994, cited in Rovai, 2004); it emphasises the social aspect of knowledge building and the role of a learning community and of social presence (Yamada, 2009, for specific reference to language learning), and enhances motivational values of being a member of group (Rogers, 1970, in Russell et al., 2006). In addition to the wiki, collaboration is supported in Collit by synchronous voiced Skype tutorials held in group. The aim of these meetings is to provide speaking practice, increase social presence, provide timely tutor support (see below) and stimulate students' initiative.

Third, Collit's wiki proves effective for implementing the community-ascurriculum model promoted by MOOCs (section 2). It is open-ended and relies on student-led learning activities and learner-generated content: the students are expected to search for, evaluate and select resources to be shared with the learning group. This is consistent with Biggs' (2003) constructive alignment between the activity and the outcomes (section 2), which, in Collit, are both learner-controlled. It is also consistent with the experiential approach to course design (section 2), in that the lack of a predefined syllabus emphasises the priority given to the learning activity and the learning process over content (Oliver and Herrington, 2003) and outcomes (Kolb, 1993), and ensures that the students take their own learning trajectory towards personalised outcomes. This encourages learning which is personally relevant, increases motivation and promotes self-regulation (MacFarlane-Dick and Nicol, 2006) for the benefit of learning. 
The community-as-curriculum model is maximised in Collit by engaging the participants not only in discerning their own learning content and resources but also in creating new learning materials and activities useful for their peers' learning. To give another concrete example, one learner, after a visit to Italy, chose to share one aspect of his experience with the other participants. He did so by selecting a relevant YouTube video on the topic of his choice and creating a set of related comprehension questions. Both media and set of questions were published on the wiki for the other students to complete the task. The responses of the other participants were different in nature. Some language corrections were suggested, most questions were answered and new related resources and learner-created activities were added. This generated additional participation, learning resources, reflection on and evaluation of own learning and that of the others. The process of creating rather than responding to questions has been found to increase the participants' ownership of the learning process and to lead to deep learning (Draper, 2009). In this instance, the teacher took the role of the student by completing the comprehension task, providing the other participants with model answers for self-assessment.

\subsection{Teacher support and feedback}

In line with the role of the teacher as portrayed by the cognitive and experiential approaches (section 2), Collit's tutor provides guidance, supports and assists the planning of student-selected learning activities. For example, although open-ended, Collit's wiki offers a broadly defined initial structure into content and grammatical themes with related activities to be expanded with students' own content. These suggested activities offer a supportive starting point for the students' initial contributions (Wheeler and Wheeler, 2009) and provide scaffolds (Wood, Bruner and Ross, 1976) to encourage focused learning.

Collit does not include formal assessment. Instead, it incorporates strategies of less-hierachical and formative assessment, by providing opportunities for peer and self-assessment (Hatzipanagos and Warburton, 2009) and students' involvement in the assessment procedure (Draper, 2009). The tutorials on Skype provide feedback based on instant response relevant to the context (Hounsell, $\mathrm{Xu}$ and Tai, 2007). Overall, the participative and formative nature of Collit's informal assessment strategy is aligned with the emphasis on interaction and collaboration and on learning as a process.

\section{The running of Collit: Preliminary findings}

At the time of writing Collit had been running for two semesters and was still work-in-progress. Five students took part in the study while a few others dropped in and out of the course due to life commitments.

It was claimed earlier that Collit's design and practice aimed to investi- 
gate the effectiveness of open online pedagogies (Pedagogy 2.0 and MOOCs' community-as-curriculum model) to support student-led language learning and learner-generated content. Experimenting with openness - that is, with the use of open content and practice in language learning — proved successful for nurturing new learning dynamics in which the students led their learning process and the creation of learning content (cf. examples in section 3). Furthermore, the fact that Collit generated open online resources (cf. the examples in section 3) ensured the benefits of multimodal and multimedia learning (Moreno and Mayer, 1999). Finally, the transparency of the dialogue between all participants, including the tutor, encouraged knowledge sharing and collaboration consistent with the design of the course outlined in section 2 .

However, other factors related to the openness of the context had a less positive impact. The optionality of Collit caused slow students' responses, intermittent participation and several drop outs. The open recruitment strategy increased the degree of mixed abilities amongst the students, derived from their different learning backgrounds and ages. This affected the creation of the materials making it difficult, at time, to reconcile the interests and abilities of the participants.

Similarly, the varying level of digital skills of the learners made it difficult to overcome technical glitches and influenced the tutor's choice of e-tools. Although the participants were expected to feel comfortable with the use of online tools, technology had to be kept as simple as possible to help reduce technical difficulties. This had an impact on the variety of Collit's learning activities.

For instance, plans had been made to introduce a Second Life component designed to support collaboration and social interaction with in-world native speakers of Italian and to capitalise on the educational opportunities offered by identity exploration in virtual worlds (Lee and Hoadley, 2007; Gee, 2007; among others). However, given the steep learning curve presented by Second Life, Collit had to resort to inviting a small number of native speakers to participate to the wiki and the Skype tutorials in order to provide more authentic social interactions.

To overcome these difficulties, future editions of Collit will include online workshops to familiarise the participants with the digital tools involved.

\section{Conclusion}

To conclude, this contribution has focused on the theoretical framework and design of Collit, an educational initiative which brought together principles of open pedagogies especially collaboration, social interaction and learningoriented informal assessment for the benefit of language learning. Although, Collit has yet to provide systematic results measuring the level of language 
proficiency achieved through its practice, several pedagogical issues related to openness have emerged which will provide guidelines for the future phases of this study and for future studies concerned with the adoption of open pedagogies for language learning and teaching.

\section{References}

Biggs, J. 2003. Aligning teaching for constructing learning. The Higher Education Academy. Retrieved January 9, 2013. Available at www.bangor.ac.uk/adu/the_scheme/ documents/Biggs.pdf.

Cormier, D. and G. Siemens. 2010. The Open course through the open door: Open course as research, learning and engagement. Retrieved February 23, 2012. Available at: net.educause.edu/ir/library/pdf/ERM1042.pdf.

Draper, S. 2009. Catalytic assessment: Understanding how MCQs can foster deep learning. British Journal of Education Technology (special issue on e-assessment), 40, pp. 285-293.

Gee, J.P. 2007. What video games have to teach us about learning and literacy. New York: Palgrave Macmillan.

Goria, C. 2012. Collaborative Italian: Pedagogy 2.0 for student-led language teaching. Paper presented at Learning Through Sharing: Open Resources, Open Practices, Open Communication (Eurocall CMC and Teacher Education SIGs Annual Workshop), Bologna, Italy.

Hatzipanagos, S. and S. Warburton. 2009. Feedback as dialogue: Exploring the links between formative assessment and social software in distance learning. Learning, Media and Technology, 34, pp. 45-59.

Hounsell, D., R. Xu and C.M. Tai. 2007. Integrative assessment: Balancing assessment of and assessment for learning. In the series Enhancement themes guides to integrative assessment, no. 2. Gloucester: Quality Assurance Agency for Higher Education. Retrieved April 11, 2010. Available at: www.enhancementthemes.ac.uk/ docs/publications/guide-no-2---balancing-assessment-of-and-assessment-for-learning. pdf? sfvrsn=16.

Jonassen, D.H. 1994. Computers in schools: Mind tools for critical thinking. University Park: Pennsylvania State: University Press.

Knowles, M. 1998. The adult learner (5th ed.). Houston: Butterworth-Heinemann.

Kolb, D. 1993. The process of experiential learning. In M. Thorpe, R. Edwards and A. Hanson (eds.), Culture and processes of adult learning. Buckingham, Oxford University Press, pp. 138-156.

Koutropoulos, A., M.S. Gallagher, S.C. Abjian, I. de Waard, R.J. Hogue, N. Ö. Keskin and O.C. Rodriguez. 2012. Emotive vocabulary in MOOCs: Context and participant retention. European Journal of Open, Distance and E-Learning (EURODL). Retrieved January 9, 2013. Available at: www.eurodl.org/?article=507. 
Lee, J. and C.M. Hoadley. 2007. Leveraging identity to make learning fun: Possible selves and experiential learning in massively multiplayer online games (MMOGs). Innovate, 3(6). Retrieved January 9, 2013. Available at: tinyurl.com/bcmbcon.

MacFarlane-Dick, D. and D. Nicol. 2006. Formative assessment and self-regulated learning: A model and seven principles of good feedback practice. Studies in Higher Education, 31, pp. 199-218.

McLoughlin, C. and M. Lee. 2008. Future learning landscapes: Transforming pedagogy through social software. Innovate 4(5). Retrieved January 9, 2013. Avaialble at: tinyurl.com/ayzugzt.

Moreno R. and R.E. Meyer. 1999. Cognitive principles of multimedia learning: The role of modality and contiguity. Journal of Educational Psychology, 91, pp. 358-368.

Moskaliuk, J., J. Kimmerle and U. Cress. 2009. Wiki-supported learning and knowledge building: Effects of incongruity between knowledge and information. Journal of Computer Assisted Learning, 25, pp. 549-561.

Oliver, R. and J. Herrington. 2003. Exploring technology-mediated learning from a pedagogical perspective. Interactive Learning Environments, 11, pp. 111-126.

Perkins, D. 2006. Constructivism and troublesome knowledge. In J.H.F. Meyer and R. Land (eds.), Overcoming barriers to human understanding: Threshold concepts and troublesome knowledge. London: Routledge, pp. 33-47.

Pop, A. 2010. The impact of new technologies in foreign language instruction: Our experience. Procedia Social and Behavioural Science, 2, pp. 1185-1189.

Rogers, C. 1979. Encounter groups. London: Penguin Press.

Rovai, A.P. 2004. A constructivist approach to online college learning. The Internet and Higher Education, 7, pp. 79-93.

Russell, J., E. Lewis, D. Swinglehurst and T. Greenhalgh. 2006. Using the online environment in assessment for learning: A case-study of a web-based course in primary care. Assessment and Evaluation in Higher Education, 31, pp. 465-478.

Smith, M.K. 2002. Malcolm Knowles, informal adult education, self-direction and andragogy. The encyclopedia of informal education. Retrieved: October 28, 2008. Available at: www.infed.org/thinkers/et-knowl.htm.

Toohey, S. 1999. Beliefs, values and ideologies in course design. In S. Toohey, Designing courses for higher education. Buckingham: Society for Research into Higher Education (SRHE) and OUP, pp. 44-69.

Usher, R., I. Bryant and R. Johnston. 1997. Adult education and the postmodern challenge: Learning beyond the limits. London: Routledge.

Vygotsky, L.S. 1978. Mind in society. Cambridge, MA: Harvard University Press.

deWaard, I., S.C. Abjian, M.S. Gallagher, R.J. Hogue, N.Ö. Keskin, A. Koutropoulos and O.C. Rodriguez. 2011. Using mLearning and MOOCs to understand chaos, emergence, and complexity in education. International Review of Research in Open 
and Distance Learning (IRRODL), 12(7). Retrieved November 29, 2012. Available at: www.irrodl.org/index.php/irrodl/article/view/1046.

Wheeler, S. and D. Wheeler. 2009. Using wikis to promote quality learning in teacher training. Learning, Media and Technology, 34, pp. 1-10.

Wood, D., J. Bruner and G. Ross. 1976. The role of tutoring in problem solving. Journal of Child Psychology and Psychiatry, 17, pp. 89-100.

Yamada, M. 2009. The role of social presence in learner-centered communicative language learning using synchronous computer-mediated communication: Experimental study. Computers \& Education, 52, pp. 820-833. 